\title{
Recent Changes in United States Extreme 3-Day Precipitation Using the R-CAT Scale
}

\author{
MARYAM A. LAMJIRI AND F. MARTIN RALPH \\ Center for Western Weather and Water Extremes, Scripps Institution of Oceanography, University \\ of California, San Diego, La Jolla, California \\ Michael D. DeTtinger \\ Center for Western Weather and Water Extremes, Scripps Institution of Oceanography, University \\ of California, San Diego, La Jolla, California, and U.S. Geological Survey, Carson City, Nevada
}

(Manuscript received 7 August 2019, in final form 29 March 2020)

\begin{abstract}
Extraordinary precipitation events have impacted the United States recently, including Hurricanes Harvey (2017) and Florence (2018), with 3-day precipitation totals larger than any others reported in the United States during the past 70 years. The rainfall category (R-CAT) scaling method is used here to document extreme precipitation events and test for trends nationally. The R-CAT scale uses thresholds of 3-day precipitation total in $100-\mathrm{mm}$ increments (starting with $200 \mathrm{~mm}$ ) that do not vary temporally or geographically, allowing for simple, intuitive comparisons of extremes over space and time. The paper that introduced the scale only required levels 1-4 to represent historical extremes, finding that R-CATs 3-4 strike the conterminous United States about as frequently as EF 4-5 tornadoes or category 3-5 hurricanes. Remarkably, Florence and Harvey require extending the scale to R-CAT 7 and 9, respectively. Trend analyses of annual maximum 3-day totals (1950-2019) here identify significant increases in the eastern United States, along with declines in Northern California and Oregon. Consistent with these results, R-CAT storms have been more frequent in the eastern, and less frequent in western, United States during the past decade compared to 1950-2008. Tropical storms dominate R-CAT events along the southeastern coast and East Coast with surprising contributions from atmospheric rivers, while atmospheric rivers completely dominate along the West Coast.
\end{abstract}

\section{Introduction}

Among four types (flooding, tropical cyclones, severe storms, and winter storms) of billion-dollar weather-driven disasters in the United States (https://www.ncdc.noaa.gov/ billions/events/US/1980-2018) since 1980, tropical cyclones have been by far the costliest and deadliest, with average costs more than 20 billion dollars and more than 140 fatalities per cyclone on average. Winter storms are next deadliest (with about 60 deaths per billion-dollar winterstorm disaster) and flooding is the next most costly (with average costs of about 5 billion dollars per "billiondollar" flood disaster). Thus, extreme storms and floods of various types are an enormous threat in today's world, even as these extreme events are projected to increase in strength and frequency with climate change, and are

Corresponding author: Maryam A. Lamjiri, masgaril@ucsd.edu likely to cause even more negative socioeconomic impacts (IPCC et al. 2012).

And ominously, the conterminous United States (CONUS) has experienced some truly remarkable and catastrophic storm events during recent years. For instance, in February 2017, a strong and warm atmospheric river $(\mathrm{AR}),{ }^{1}$ in the midst of a winter with an unusual number of West Coast ARs, made landfall in Northern California. In combination with other problems (e.g., Vano et al. 2019), the storm sequence resulted in failures of operating and emergency spillways safeguarding Oroville Dam, the tallest dam in North America (Vahedifard et al. 2017; White et al. 2019),

\footnotetext{
${ }^{1}$ Atmospheric rivers (ARs) are long and narrow corridors with strong horizontal water vapor transport that are usually associated with extratropical cyclones (American Meteorological Society 2020).
} 
putting almost 200000 people downstream at risk. In August of 2017 in southeastern Texas, landfalling Hurricane Harvey yielded unprecedented precipitation totals, on the order of 33 trillion gallons of rain (Pacheco 2017 ), and became one of the costliest ( $>\$ 125$ billion in damages) tropical cyclones on record (National Hurricane Center 2018). In 2018, the following year, Hurricane Florence made landfall in the Carolinas, depositing equally unprecedented precipitation totals, causing extreme flooding and damages. Then, in 2019, Tropical Storm Imelda made landfall in southeastern Texas (Jenner 2019), depositing precipitation totals only surpassed previously in the area by Hurricane Harvey.

Occurrence of these extreme storms in such a short time naturally raises the question whether they reflect a new precipitation regime wherein higher frequencies of such extremes are now to be expected. If so, these changes must be factored into the urgency of actions to reduce greenhouse gas emissions and into preparations to adapt to and minimize their catastrophic impacts. A number of recent studies have explored how climate change has already altered the hydrologic cycle and how these changes will intensify or abate in the future. Amplification of heavy precipitation has been demonstrated in observations from many parts of the world including CONUS, southern Canada, southeastern Australia, Norway, and northern Japan (Iwashima and Yamamoto 1993; Groisman et al. 1999; Easterling et al. 2000a,b; Alexander et al. 2006). Increases since the 1930s in CONUS of the number of heavy precipitation days per year and the frequency of multiday (1-7 days) extreme precipitation events with recurrence intervals longer than 1 and 5 years have been recorded (Karl et al. 1996; Karl and Knight 1998; Groisman et al. 1999; Kunkel et al. 1999), including recent studies that have focused more specifically on trends in extreme precipitation from landfalling tropical storms and hurricanes in the southeastern United States (e.g., Kunkel et al. 2010; Bishop et al. 2019). Very specifically, several recent studies have attributed significant components of the remarkable rainfall totals from Hurricane Harvey to climate change (Risser and Wehner 2017; van Oldenborgh et al. 2017; Emanuel 2017; Wang et al. 2018). Groisman et al. (2001) documented increases in heavy precipitation in western United States and in winter extremes in the eastern United States during the last decades of the twentieth century. Kunkel (2003) showed a significant increase in the frequency of extreme precipitation events in the United States since 1920s and 1930s. Higgins and Kousky (2013) compared daily precipitation over the CONUS between 1950-79 and 1980-2009 and identified increased light, moderate, and heavy precipitation in recent decades in some parts of CONUS, especially in the
TABLE 1. Definition of R-CAT events and modifications to the original RD12 R-CAT scale.

\begin{tabular}{lcc}
\hline \hline & \multicolumn{2}{c}{$\begin{array}{c}\text { Defining 3-day precipitation } \\
\text { thresholds }(\mathrm{mm})\end{array}$} \\
\cline { 2 - 3 } R-CAT level & RD12 & This study \\
\hline R-CAT 1 & $200 \leq P<300$ & $200 \leq P<300$ \\
R-CAT 2 & $300 \leq P<400$ & $300 \leq P<400$ \\
R-CAT 3 & $400 \leq P<500$ & $400 \leq P<500$ \\
R-CAT 4 & $P \geq 500$ & $500 \leq P<600$ \\
R-CAT 5 & - & $600 \leq P<700$ \\
R-CAT 6 & - & $700 \leq P<800$ \\
R-CAT 7 & - & $800 \leq P<900$ \\
R-CAT 8 & - & $900 \leq P<1000$ \\
R-CAT 9 & - & $P \geq 1000$ \\
\hline
\end{tabular}

Great Plains and lower Mississippi Valley during winter and fall seasons, with decreases in wintertime precipitation in parts of the southeastern United States and Pacific Northwest.

In these studies, a variety of methods were used to characterize precipitation extremes, methodological differences that impact results (Barlow et al. 2019). Some studies defined extremes based on fixed thresholds of daily or multiday precipitation totals, some used percentile-based definitions, while others evaluated recurrence intervals. Each approach has its advantages and disadvantages. Recurrence interval and percentilebased approaches characterize precipitation extremes by region-specific metrics that directly accommodate the fact that what is extreme in one area may not be considered extreme in another and that some areas never experience extremes as large as the largest in the U.S. record. However, for other purposes, they can be limiting in that they complicate comparisons between different locations. Furthermore, thresholds used in the percentile-based and recurrence interval-based approaches depend on overall distribution of magnitude and frequency of precipitation events in ways that are likely to be impacted by climate change. Consequently, they require nonstationary assumptions and methods (Milly et al. 2008) that make tracking of temporal changes challenging. Finally, the concept of recurrence interval may be complicated and hard for the public to understand.

With these considerations in mind, Ralph and Dettinger (2012, hereafter RD12) introduced a complementary characterization of extreme precipitation, the rainfall category (R-CAT) scale, which is based on a fixed set of 3-day precipitation thresholds (Table 1). Because this scale is based on the same precipitation thresholds everywhere, comparing extremes from region to region, and through time, is trivial. However, some regions simply have never experienced R-CAT 
levels of precipitation in their historical records and thus are largely excluded from R-CAT-based analyses. The R-CAT scale was designed specifically to address only the very most extreme precipitation episodes ever recorded at CONUS weather stations, with most stations only reaching the larger R-CAT levels once or twice, if at all, during their entire periods of record. This R-CAT strategy essentially substitutes consideration of the far extremes of precipitation among many stations for consideration of more numerous less-extreme episodes at individual stations [i.e., if the R-CAT thresholds had been set lower, as in Slinskey et al. (2019)].

In this study, we use RD12's R-CAT scale to analyze the climatology of extreme 3-day precipitation totals from 3501 weather stations across CONUS, and compare R-CAT events between 1950-2008 and 2009-19. Our goals are 1) to provide a more complete characterization of R-CAT level events and underlying meteorological mechanisms (Barlow et al. 2019) and 2) to contrast R-CAT level events in 2009-19 to R-CATs in the historical period (1950-2008) analyzed by RD12.

Section 2 of this paper revisits the R-CAT strategy, modifying it to allow more detailed analysis and describing data sources and methods. Section 3 presents spatial and temporal distributions of storms rising to R-CAT levels, their causes and impacts, and observed trends in their frequencies and characteristics. Conclusions are discussed in section 4 .

\section{Data and methodology}

\section{a. Data: Precipitation observations}

Daily precipitation observations used in this analysis are from the Global Historical Climatology NetworkDaily (GHCN-Daily) dataset version 3 (Menne et al. 2012). This dataset includes station-based observations of different climate variables from multiple sources and is regularly updated. The latest set of quality control checks are applied routinely to the full dataset, from start to finish, to ensure a coherent and uniformly quality controlled dataset. A total of 3501 stations in CONUS, each with less than $20 \%$ missing observations (after removing observations with quality assurance flags) each year for at least 50 years from 1950 to 2019, were used in the present analyses. Among these stations, $26 \%$ are located in western United States (west of $105^{\circ} \mathrm{W}$ ) and the rest are located in eastern United States (east of $105^{\circ} \mathrm{W}$, Fig. 1a). Densities of the observational networks vary from place to place, with fewer stations west of $105^{\circ} \mathrm{W}$ than east of that meridian, but for the most part coverage is adequate to describe the spatial locations and extents of major storm events. The annual numbers of stations used in this study are shown in Fig. 1 b.

\section{b. Methodology}

\section{1) R-CAT EVENTS}

Multiday (as opposed to daily) precipitation totals are usefully analyzed because of their relevance to larger (spatial) scale regional hydrologic impacts. RD12 argued that 3-day precipitation totals, in particular, provided a useful representation of storms that yield flooding and damages in medium to large river basins. Following their methodology, R-CAT events are categorized, in this study as in RD12, on a station-by-station basis and are 3-day periods during which total precipitation reaches or exceeds one of the thresholds listed in Table 1. This R-CAT definition needs to also address instances when intense precipitation continues for more than 3 days. Although for some purposes, a longer window length might have been preferred, here (as in RD12) the 3-day window is maintained for simplicity of interpretation's sake. However, if during an extended R-CAT-level storm, a station's precipitation totals reach R-CAT levels during a longer-than-3-day sequence of overlapping 3-day periods, the event is identified by the 3-day period with the largest precipitation total. As in RD12, R-CAT events are considered back-to-back if one starts the day after the other one ends and are then treated as distinct R-CAT events. Often, almost all extreme precipitation may fall in just only one day. The R-CAT event is then identified as the 3-day period centered on that extreme day. This limits the usefulness of R-CAT analysis for most localized flashflooding storms.

\section{2) R-CAT EPISODES}

The storms that produce R-CAT level precipitation generally impact multiple stations at a time, and so, in order to extend the analyses to whole-storm levels, R-CAT episodes were defined by RD12 and are redefined (to allow greater spatial and temporal specificity) here. R-CAT episodes capture the larger spatial-scale characteristics of the R-CAT level storms by considering precipitation totals and patterns among multiple stations. That is, R-CAT episodes expand the concept of R-CAT events to include precipitation extremes occurring at multiple stations (as in RD12) but are defined here in a way modified from RD12 and designed to provide more spatial specificity.

In RD12, episodes were only used to count events occurring simultaneously within the eastern versus western halves of CONUS. Figure 2 describes the local cluster analyses used to define R-CAT episodes in the present 


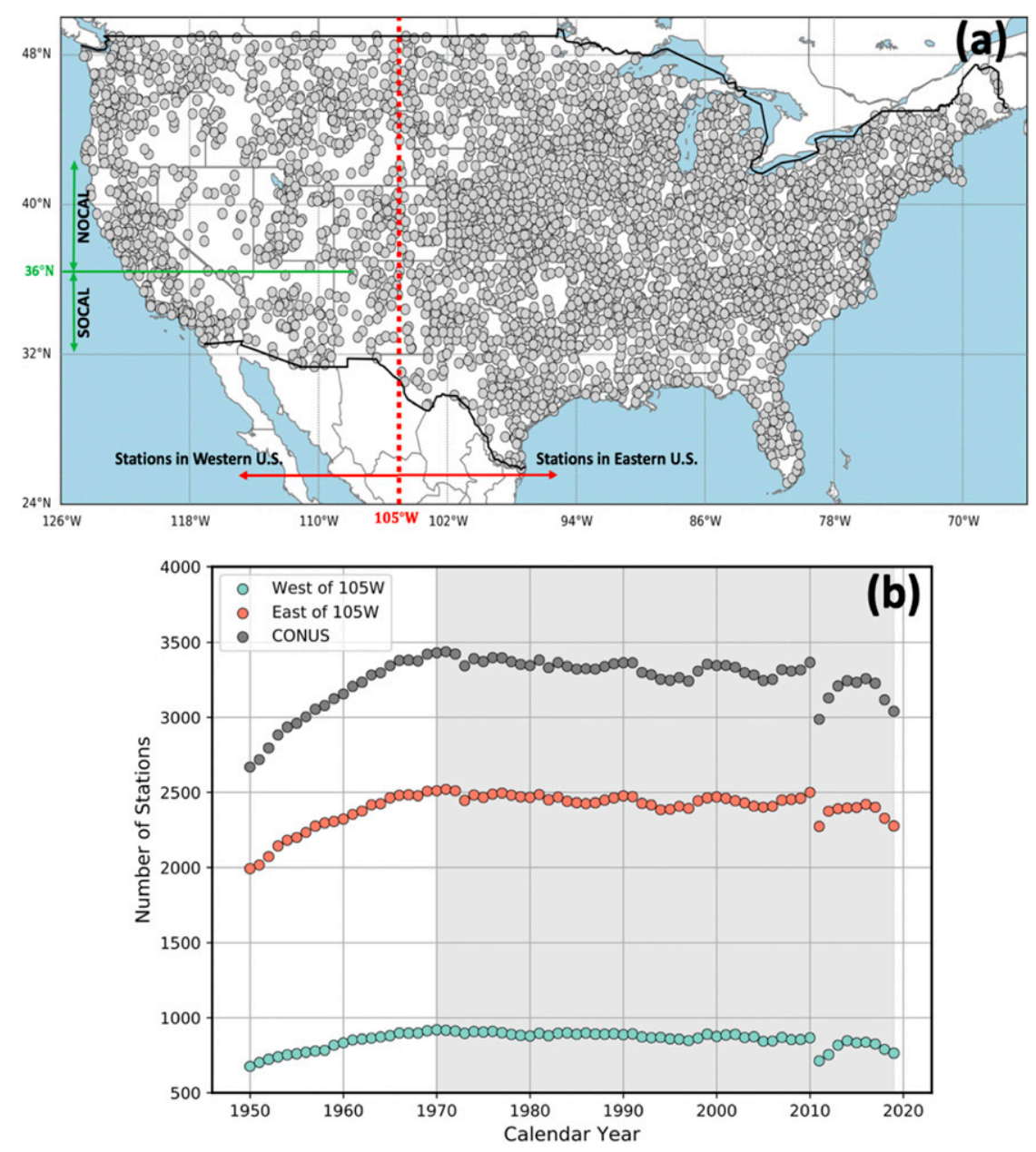

FIG. 1. (a) Location of stations with at least 50 years of record from 1950 to 2019 and less than $20 \%$ missing values each year. The horizontal solid green line shows the zonal line at $36^{\circ} \mathrm{N}$ which separates Northern (NOCAL) and Southern (SOCAL) California in this study. Although traditionally the divide between the eastern and western United States has been set at $100^{\circ} \mathrm{W}$ for water supply purposes (Stegner 1953), the western extent of stations experiencing R-CAT events historically has been farther west, nearer the northwestern boundary of Texas (see Fig. 3a), so that using $100^{\circ} \mathrm{W}$ would have artificially added eastern R-CAT events to the western totals. Instead, in RD12 and the present study, the dashed red meridian at $105^{\circ} \mathrm{W}$ is used as the dividing line. (b) Annual number of stations in eastern and western United States that meet the requirement of having at least 50 years of less than $20 \%$ missing values each year. The jump in 2010 is an artifact of revisions associated with the transition of cooperative-network database from USHCN to GHCN in that year.

study. Temporal and spatial connectivity between the R-CAT events making up an episode is assured through the iterative clustering algorithm, with R-CAT events within each episode required to either overlap with or occur back-to-back with respect to at least one preceding R-CAT event in that episode (temporal connection). R-CAT events within each episode are also required to occur within a maximum distance of $500 \mathrm{~km}$ from at least one other station experiencing R-CAT level precipitation in the same episode (spatial connection).

The distance threshold applied here was arbitrarily chosen to be $500 \mathrm{~km}$ in this study; that threshold is not adjusted to account for region-specific storm characteristics or network densities. Moreover, the clustering algorithm is applied only to stations that have experienced R-CAT events, excluding stations experiencing lower-than-RCAT-level precipitation. Thus, there may be instances when two separate storms are categorized as one episode, resulting in underestimation of the frequency of R-CAT episodes, and instances when one storm is divided into multiple small episodes, resulting in overestimation of the frequency of R-CAT episodes.

Despite this limitation, this iterative grouping protocol for identifying "episodes" succeeds in characterizing 


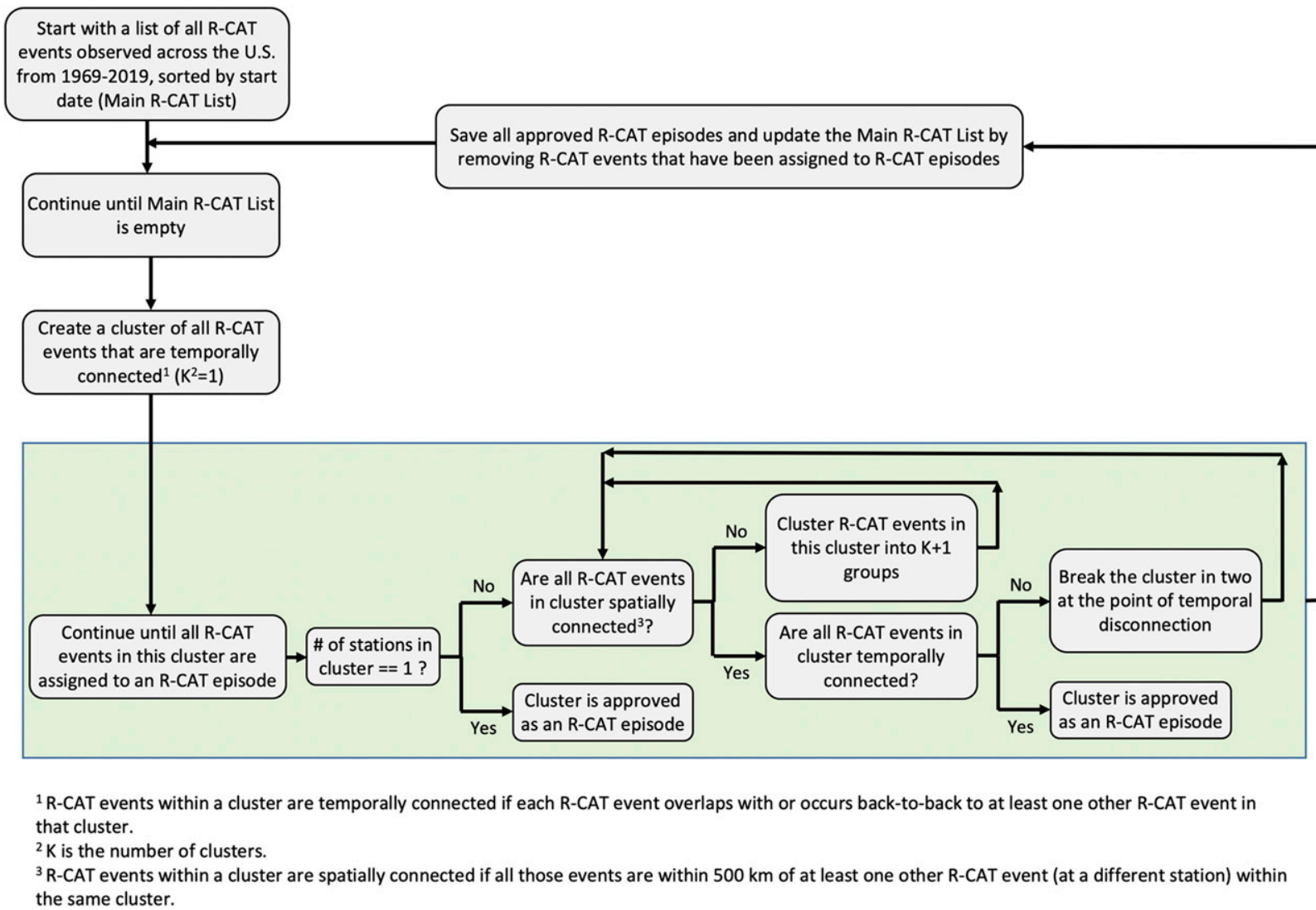

FIG. 2. Step-by-step description of the clustering algorithm used to delineate R-CAT episodes.

large-scale storms and storm sequences in terms of multiday, multistation collections of extreme precipitation reports. This characterization allows spatial extents and temporal durations, as well as levels of extremity, of storms to be analyzed in the historical record.

\section{3) Chronology of ATMOSPHERIC RIVER LANDFALLS}

A chronology of AR landfalls along the U.S. West and East Coasts from Guan and Waliser (2015) is used here to link R-CAT storms to nearby ARs. The Guan and Waliser (2015) AR chronology is based on 6-hourly fields of Integrated Vapor Transport (IVT) from the National Centers for Environmental Prediction (NCEP)/National Center for Atmospheric Research (NCAR) reanalysis dataset for the period of 1950-2015. Guan and Waliser (2015) identify ARs based on several geometrical and IVT-intensity criteria, including thresholds for the width to length ratio and directional coherence of intense IVT features. The chronology is suitable for this analysis because of its length of record and because its geometrical criteria are designed to distinguish ARs from other atmospheric phenomenon such as closed lows and tropical cyclones.
An R-CAT episode is considered "AR-related" if there is at least one 6-h temporal overlap between the episode and a 12-h or longer AR landfall on the nearest coastal grid cell to the episode center.

\section{Results}

a. Spatial and temporal distributions of R-CAT events
and episodes

\section{1) SPATIAL Distribution OF 3-DAY R-CAT EVENTS}

Following RD12, maximum levels of R-CAT events recorded at each station between 1950 and 2019 are presented in Fig. 3a. The overall pattern presented in Fig. 3a is similar to that shown by RD12's Fig. 3, with precipitation events stronger than R-CAT 3 observed almost entirely at stations along the U.S. West Coast-especially along the California Coastal Ranges and Sierra Nevada mountains - and at southeastern stations along the Gulf Coast and U.S. East Coast. Events in the R-CAT 1 and 2 range (gray and green dots in Fig. 3a) fill in gaps in the patterns of stronger R-CATs, 

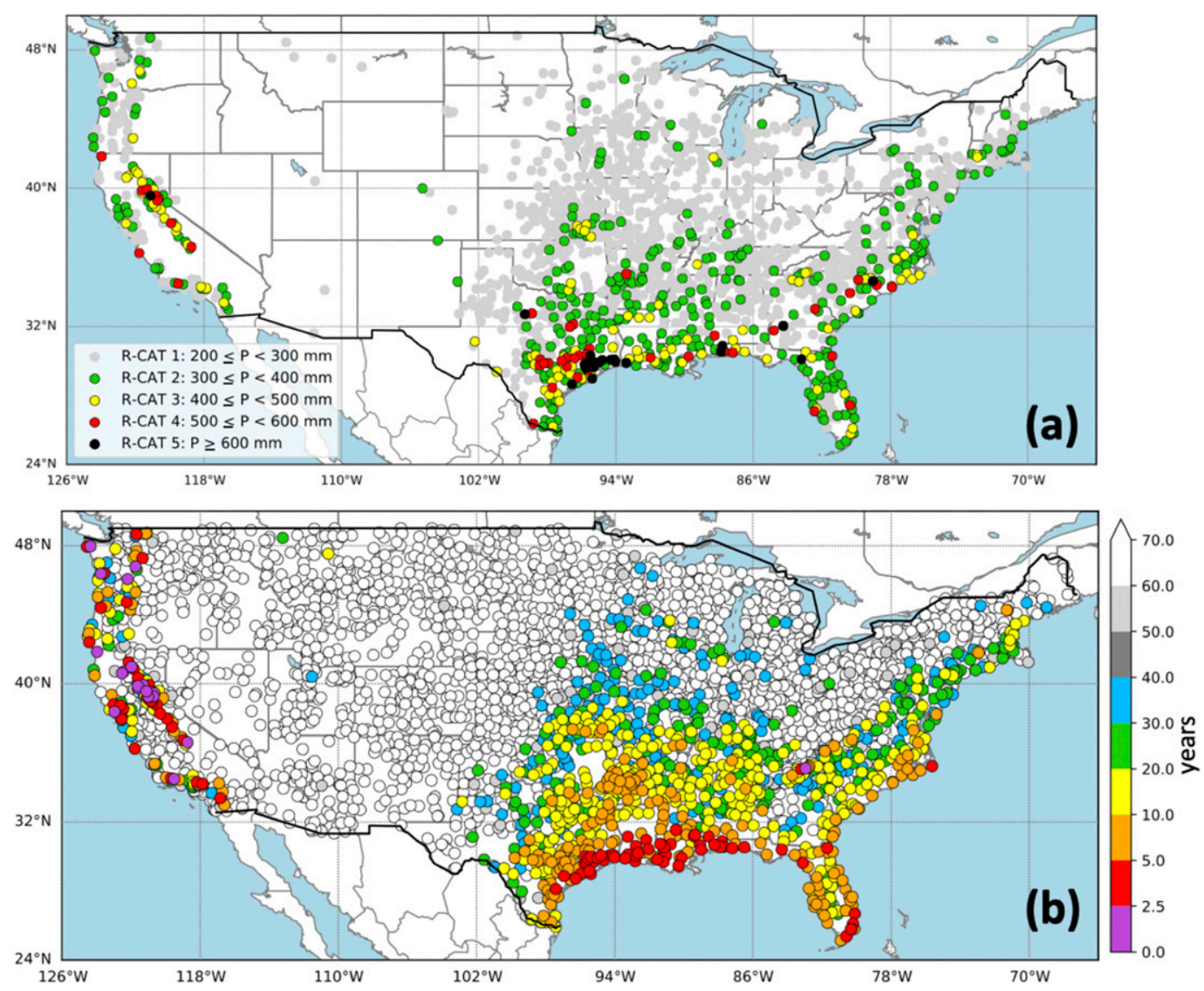

FIG. 3. (a) The highest R-CAT level reached at each station and (b) the recurrence interval of 3-day precipitation totals reaching at least the R-CAT 1 level (200 mm), 1950-2019.

especially extending northward and inland from the Gulf Coast. Along the northern tier of states and throughout the interior west, most or all stations have never recorded R-CAT precipitation extremes.

Because of recent unprecedentedly large R-CAT events, in this study 5 more R-CAT levels (R-CAT 5-9) have been added to RD12's scale (Table 1). In the period of record, R-CAT 6 storms have been recorded twice (in central Texas, 1978, and along the northeastern Texas coast, Tropical Storm Imelda, 2019), while R-CAT 7 and 9 storms have only been recorded once each anywhere (in the Carolinas, Hurricane Florence, 2018, and along the northeastern Texas coast, Hurricane Harvey, 2017). R-CAT 8 has never been recorded at any of the 3501 stations. Therefore, in Fig. 3a, R-CATs 5 and larger are grouped together.

Many studies analyzing extreme precipitation have applied the concept of return periods (e.g., Karl and Knight 1998; Karl et al. 1996; Groisman et al. 1999; Kunkel et al. 1999). To give a sense of the extremity and rarity of R-CAT events for comparison to these studies, Fig. $3 \mathrm{~b}$ shows the empirical return periods of R-CAT events for the period from 1950 to 2019. These intervals were estimated at each station as the ratio of total number of years of precipitation record to the number of years with annual maximum 3-day precipitation totals exceeding $200 \mathrm{~mm}$ (R-CAT 1 or larger).

In the period of record studied here, R-CAT events have occurred much more often along the coasts, especially the U.S. West Coast (Fig. 3b). Stations in California shown in purple have experienced R-CAT events at least twice as often as orange and yellow stations and at least 10 times as often at the stations in green and blue. The stations in White have never experienced R-CAT events. Reflecting this, R-CAT return periods in California and especially over northern Sierra Nevada are the shortest in CONUS, even compared to southeastern areas that are frequently impacted by hurricanes and tropical storms. Twenty-year or greater R-CAT return periods, akin to the level of more general class of storms studied by USGCRP (2017), correspond to all the colors between yellow and purple in Fig. 3b; every other station in Fig. 3 b has a 20 -yr storm that is significantly less extreme than the R-CAT scale. 

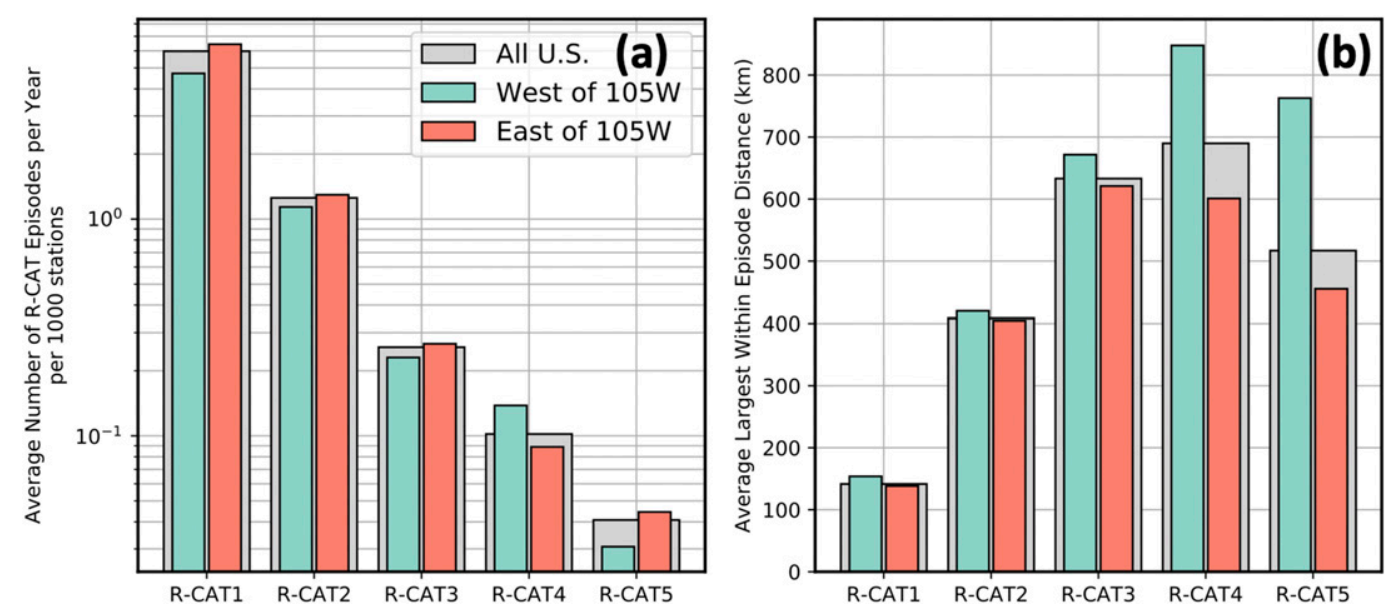

FIG. 4. (a) Average number of R-CAT episodes per year per 1000 stations and (b) average largest within-episode distance, 1950-2019.

\section{2) Average characteristics of R-CAT EPISODES}

Average characteristics of R-CAT episodes attaining different R-CAT levels with centers located anywhere in the United States, western United States (west of $105^{\circ} \mathrm{W}$ ), or eastern United States (east of $105^{\circ} \mathrm{W}$ ), are shown in Fig. 4a. On average, the number of R-CAT episodes declines with increases in their extremity in each region. Similar to RD12 findings, the frequency of R-CATs 1-4 is comparable in eastern and western United States when normalized by the number of stations in each region, despite differences in network density. Evidently the networks in both regions are dense enough to detect comparably representative numbers of R-CAT level storms. Normalized frequencies of higher-level R-CAT episodes, however, are notably lower in western than eastern United States (Fig. 4a). In the period studied here, 1950-2019, R-CAT 5 episodes have been recorded only twice (which amounts to 2.15 times per 1000 stations) in western United States but 12 times (4.67 times per 1000 stations) in eastern United States.

The areal extent of R-CAT episodes, approximated by the maximum distance between stations during an average episode, is larger in western than eastern United States (Fig. 4b). This finding holds true for all R-CAT levels with differences between the spatial extents of episodes in western and eastern United States increasing rapidly for stronger R-CAT levels. R-CAT 3 and stronger episodes, on average, have larger areal extents than smaller R-CAT episodes in each region. As will be discussed in section 3b, R-CAT episodes in western United States are almost entirely associated with the landfall of ARs that generally impact large areas (large numbers of stations) due to their large scale (typically $>500 \mathrm{~km}$ wide) and their tendency to progress southward from wherever they make landfall along the U.S. West Coast.

\section{3) SEAsonality of R-CAT EPISOdes}

R-CAT episodes are experienced in markedly different seasons from East to West Coast regions. The majority of R-CAT episodes occur during March-October and October-March in eastern and western stations, respectively (Fig. 5). In western United States, R-CAT1 episodes have occurred in all months of the year, but R-CAT 2 and stronger episodes have exclusively occurred during October-May (Fig. 5b). In eastern United States R-CATs 1 and 2 have been experienced in all months, but stronger R-CAT episodes are confined almost entirely to the March-October season. The few R-CAT 6 and stronger episodes have only occurred between August-September (Fig. 5c). These seasonal differences reflect important differences between the meteorological mechanisms (storm types) that have historically caused the R-CAT episodes.

\section{b. Meteorology of coastal R-CAT storms}

In this section, meteorological processes associated with R-CAT episodes are analyzed for five coastal regions: Southern California (SOCAL), Northern California (NOCAL), Pacific Northwest (PNW), Gulf and southeastern coasts (G\&SEC), and central and northeastern coasts (C\&NEC; Fig. 6a). Four storm types are considered here: hurricanes, tropical storms-tropical depressionssubtropical storms (TS-TD-STS), pure ARs, and mixed ARs. Processes not identified to be part of any of these four groups, are referred to as "other." Notably, several recent studies have focused specifically on ARs in the 

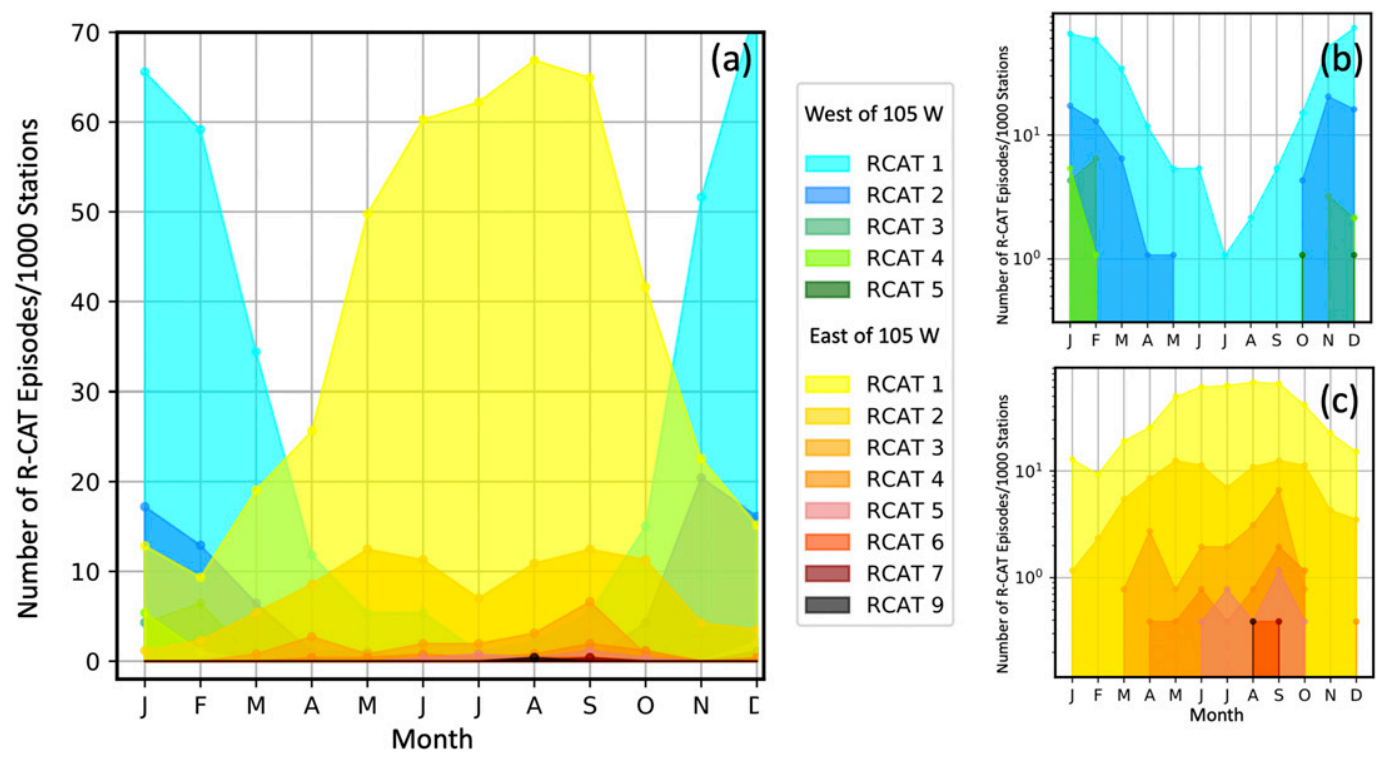

FIG. 5. (a) Total number of R-CAT episodes that have occurred in each month (1950-2019) per 1000 stations for eastern and western U.S. stations. (b) As in (a), but with logarithmic y axis for western U.S. stations. (c) As in (b), but for eastern U.S. stations.

eastern United States and along the U.S. East Coast, finding contrasts between these ARs and the more studied ARs of the U.S. West Coast (Moore et al. 2012; Mahoney et al. 2016; Debbage et al. 2017; Miller et al. 2019); nonetheless, in this study the ARs identified by Guan and Waliser (2015) are considered to be ARs whether on East or West Coast.

The "mixed AR" category, in the present analysis, refers to an R-CAT episode that overlaps with a time when both an AR and a hurricane or TS-TD-STS are present somewhere along the coast in the same region as the R-CAT episode. The term "mixed AR" is used because separate precipitation contributions from ARs, hurricanes, and TS-TD-STS during these episodes have not been distinguished here. Instead, precipitation in those R-CAT episodes are assumed to be associated with an unknown combination of the storm processes. Pure ARs, on the other hand, refer to ARs not accompanied by a hurricane or TS-TD-STS. All ARs impacting the West Coast are assumed here to be pure ARs.

Ralph et al. (2019) recently introduced a scale for the strength of ARs that divides ARs into five categories (from AR 1 to AR 5) based on a combination of maximum IVT intensity and AR duration. This AR-CAT scale is used here to further categorize pure ARs and mixed ARs into two AR-CAT ranges, 1-2 and 3-5. The East and West Coast regions have been impacted by 407 and 1467 R-CAT episodes in the period of analysis, respectively, with the rare cases of R-CATs 6 and stronger only being recorded in G\&SEC. On the West Coast, more than $90 \%$ of R-CAT episodes have coincided with landfalling ARs (e.g., Fig. 6b). More than two-thirds of these episodes were caused by AR-CAT 1-2 ARs (Figs. 6b,c), largely because AR-CAT 1-2 make landfall much more often than higher AR-CAT categories, especially in SOCAL. However, $43 \%, 65 \%$, and $100 \%$ of R-CATs 3 and stronger have coincided with ARCATs 3-5 in SOCAL, NOCAL, and PNW, respectively (Fig. 6d). Surprisingly, in the Guan and Waliser (2015) chronology, ARs also underpin substantial numbers of R-CAT episodes along the East Coast. About 48\% (45\%) of all R-CAT episodes in the G\&SEC (C\&NEC) area have been AR-related, of which $30 \%$ ( $40 \%$ ) coincided with mixed AR conditions (Fig. 6b). Indeed, more R-CAT episodes, when R-CAT 1 storms are included, have coincided with ARs along the East Coast than with hurricanes and TS-TD-STS, especially in C\&NEC. However, the fraction of R-CAT $\geq 2$ episodes coinciding with pure ARs declines while the fraction associated with hurricanes and TS-TD-STS (both acting alone or when mixed with ARs) increases (Figs. 6c,d). About half of all hurricanes and TS-TD-STS yielding R-CAT episodes in G\&SEC and C\&NEC have been accompanied by ARs. In both East Coast regions, the fraction of R-CAT episodes due to unclassified (other) processes decline for stronger R-CAT levels.

To place these R-CAT types and frequencies into perspective, the fractions of U.S. billion-dollar disasters from 1980 to 2018 (https://www.ncdc.noaa.gov/billions/ events/US/1980-2018) associated in time with various 

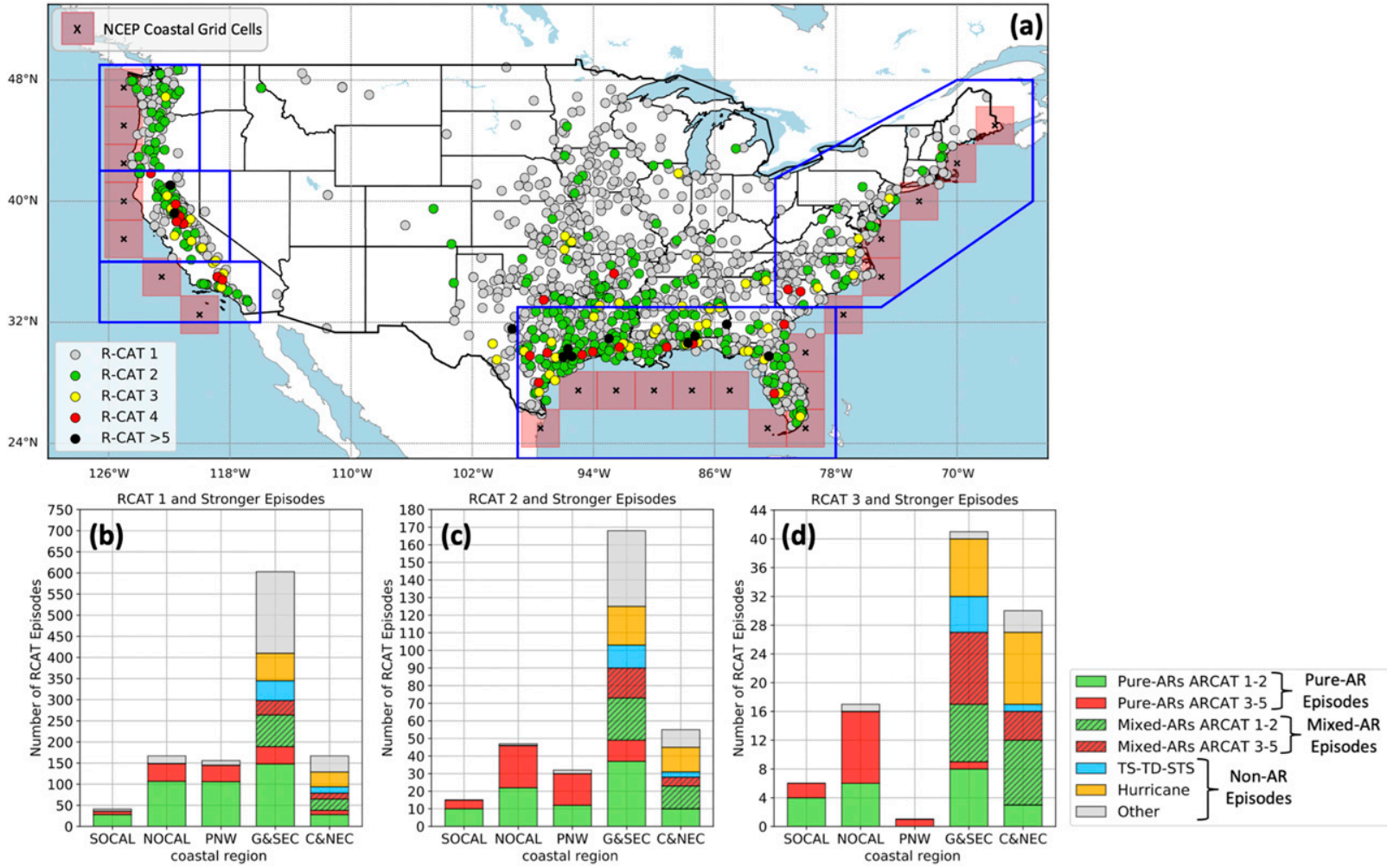

FIG. 6. (a) Center location of the R-CAT episodes, 1950-2015, colored based on their R-CAT levels with blue polygons showing coastal regions used in (b)-(d). (b)-(d) The number of R-CAT 1 and stronger, R-CAT 2 and stronger, and R-CAT 3 and stronger episodes, respectively, in each coastal region associated with pure ARs (solid green and red bars), mixed ARs (ARs mixed with hurricanes and tropical storms, hatched green and red bars), and non-ARs [tropical storms, tropical depressions, and subtropical storms (TS-TD-STS), hurricanes, and other processes, shown by blue, orange, and gray bars, respectively].

storm types and R-CAT levels were also analyzed. R-CAT storm episodes have occurred at the same time as about $90 \%$ or more of the floods and tropical cyclones that have produced billion-dollar disasters historically. R-CAT episodes have coincided in time with almost $60 \%$ and almost $30 \%$ of the severe storm and winter storm disasters, respectively. In terms of the role of storm intensities, R-CATs 3 and stronger, although much less numerous than R-CAT 1 and 2s (e.g., Fig. 4), have coincided with about $34 \%$ of the flooding, and $29 \%$ of the tropical cyclone, billion-dollar disasters. Relatively few of the severe and winter storm disasters have been tied, in time, to these higher R-CAT levels.

\section{c. Trends in 3-day precipitation totals and R-CAT storms}

One of the main goals of the current study was to place several recent extremely high R-CAT events into their historical context. These extremely high R-CAT events were-by far-the largest R-CAT storms ever recorded, Hurricane Harvey (R-CAT 9) over the Houston, TX, area in 2017 and Hurricane Florence (R-CAT 7) over the Carolinas in 2018. The strongest R-CAT storm recorded before these two was an R-CAT 6 event resulting from an interaction between the remains of two tropical storms (Amelia and a storm from over the eastern Pacific; Schroeder et al. 1987) over northeastern Texas in August 1978. More recently still, landfalling Tropical Storm Imelda yielded an R-CAT 6 episode in 2019. The remarkable magnitudes of the largest 3-day totals in each year from 2017 to 2019, compared to previous years, are evident in Fig. 7a.

\section{1) TRENDS IN 3-DAY PRECIPITATION EXTREMES}

To begin to contextualize these recent extremes, Fig. 8a maps observed trends in annual maximum 3-day precipitation totals for the period of 1950-2019 (Fig. 8a). In the eastern United States, 3-day maxima at clusters of stations across the central and northern Midwest, Gulf Coast, and central and northeast coast (rectangle A1 in Fig. 8a) have increased significantly during this period, in keeping with other historical analyses in the literature and with climate change projections (e.g., USGCRP 2017, and references therein) that observe or anticipate significant increasing trends in extremes there. In contrast, significant declines in annual 3-day maxima have 
(a)
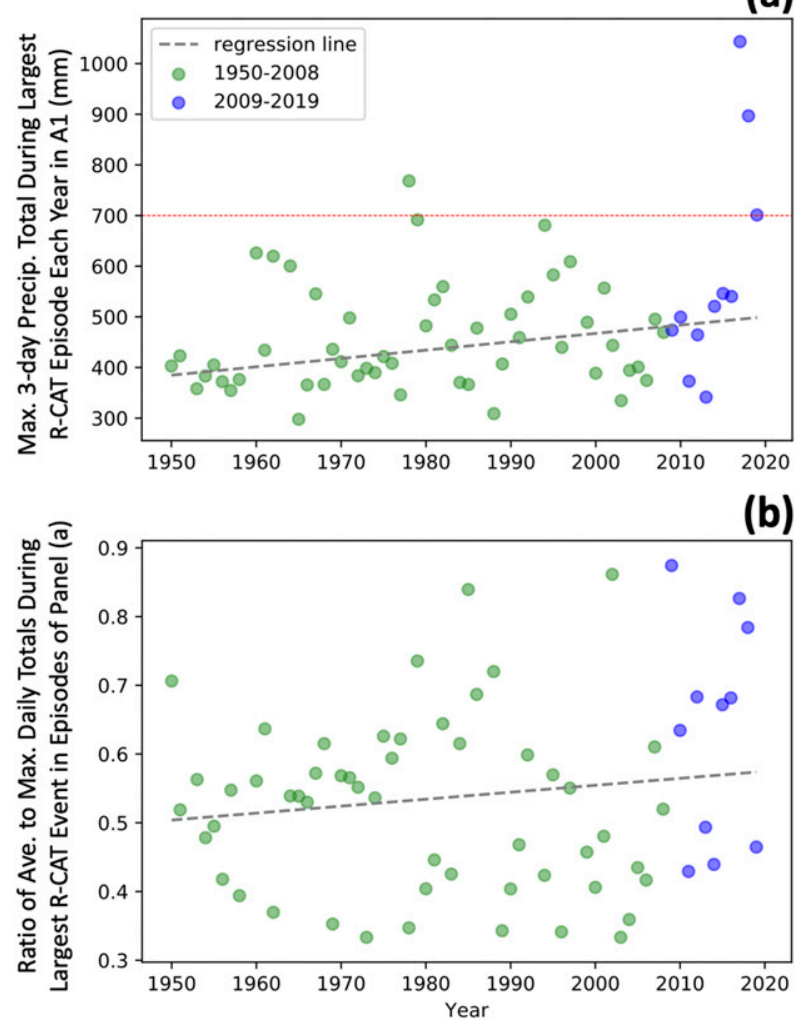

FIG. 7. (a) Maximum 3-day precipitation total during the strongest R-CAT episode recorded each year in A1 region (shown in Fig. 8), (b) the ratio of average to maximum daily precipitation total during the largest R-CAT event in episodes in (a).

been observed at 36 out of 198 stations in Northern California and coastal Oregon (rectangle A2 in Fig. 8a) with remaining 162 stations showing insignificant trends and only one station showing significant increasing trend. A small cluster of stations in northwestern Washington displays increasing trends. The declines in 3-day maxima across Oregon and Northern California are broadly in keeping with reports of modest wintertime declines there (in a regional average) of daily 20 -yr return-level precipitation totals by USGCRP (2017), for the Fourth National Assessment. These declines do not agree with projected intensification of extremes in that region in response to increasing greenhouse gas concentration (USGCRP 2017); the declines thus probably reflect some aspect of the naturally occurring, long-term (multidecadal) climate fluctuations that are particularly strong in that region (e.g., Mantua et al. 1997; McCabe and Dettinger 2002). The positive trends in eastern United States, as well as the largest negative trends along the West Coast, exceed $1.5 \mathrm{~mm} \mathrm{yr}^{-1}$, which is large enough to demote or promote R-CAT episodes by one R-CAT category over the course of the 70 -yr period analyzed here.

Time series of annual maximum 3-day precipitation totals for the 30 stations with largest positive or negative trends in the A1 and A2 areas (Fig. 8a) are shown in Fig. 8b. Period-of-record tendencies toward larger 3-day precipitation maxima in stations within $\mathrm{A} 1$ and smaller 3-day precipitation maxima in stations within A2 are evident. To assess the sensitivity of observed trends to the start and end year of the periods of record at the stations analyzed, trends are calculated for periods with different start and end years in Fig. 8c, with significant trends. For the majority of tested record lengths, significant increasing (decreasing) trends are observed in A1 (A2). However, the magnitude of average trends varies with start and end dates of analysis.

Seasonal trends in eastern United States are mostly positive with the exception of significant negative trends at a few stations in southern Florida during SeptemberNovember (SON), and in southeastern United States during March-May (MAM). The most significant positive trends in seasonal maximum 3-day precipitation totals are observed during DJF in a cluster of stations in northern Texas and central Great Plains and during SON in three clusters, one in northern Great Plains, one extending from Louisiana in the Gulf Coast to Ohio, and one along the central and northeast coast (Fig. 9).

Analysis of maximum 3-day precipitation totals by seasons further indicate that the extremes decline in December-February (DJF) at stations in southern Sierra Nevada, Northern California, and Pacific Northwest and in SON at stations in Southern and Northern California. Significant increasing trends are observed in some stations in northern coastal Washington during SON and with lower magnitudes during MAM. Trends are mostly small and nonsignificant during MAM and June-August (JJA) in western stations (Fig. 9).

\section{2) COMPARISON OF R-CAT EVEnTS AND EPISODES FROM 1950-2008 TO 2009-19}

Consistent with the negative trends in annual maximum 3-day precipitation totals along the northwest coast and positive trends in most of eastern United States, the average number of stations reaching R-CAT levels (at least $200 \mathrm{~mm}$ in a 3-day period) each year has been smaller in the west and larger in the east in the past decade compared to 1950-2008 (Fig. 10). Increases in the numbers of stations reaching R-CAT levels in the east and declines in the west are indicated for all R-CAT levels. The magnitude of these differences increases for the higher R-CAT levels (Fig. 10e).

Due to the larger area and greater number of stations in eastern United States, the overall number of R-CAT 
(a) Observed Trends in Annual Maximum 3-day Precipitation Totals, 1950-2019

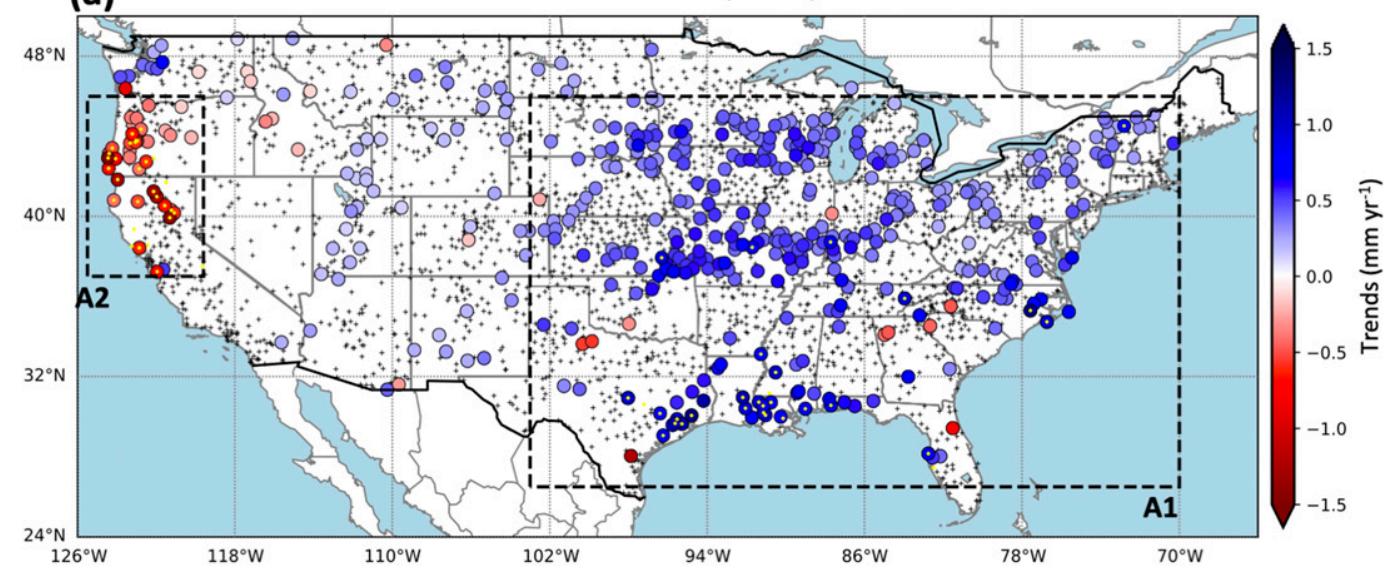

(b)

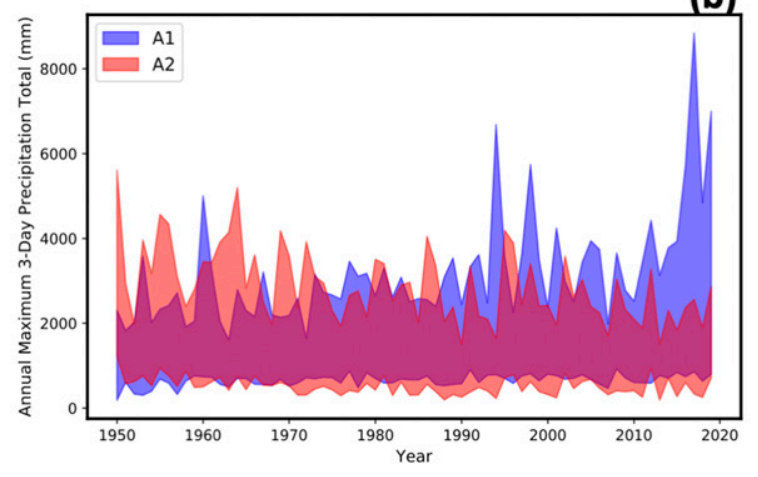

A2

(c)

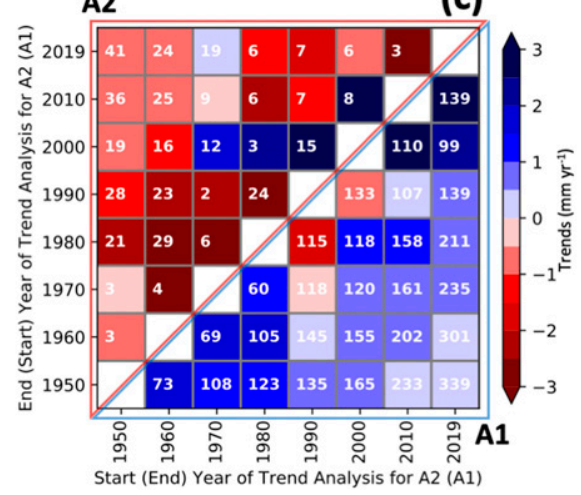

FIG. 8. (a) Observed trends in annual maximum 3-day precipitation totals 1950-2019. At each station only years with less than $20 \%$ missing values are used to calculate the trend (at least 50 years meet this criterion at each station). Blue and red circles represent stations with trends significantly different from 0 at a $95 \%$ confidence level. Trends are estimated based on Kendall's slope estimator algorithm. The significance of trends is estimated using the Kendall's $\tau$ statistic with a null hypothesis that the fluctuations are random in time. The smaller + markers represent stations where the null hypothesis could not be rejected. A1 and A2 are areas referenced in (b) and (c). (b) Time series of annual maximum 3-day precipitation totals at 30 stations in A1 and A2 with highest magnitudes of trends that are shown by yellow dots in (a). The shaded blue and red regions show the range of annual maximum 3-day precipitation totals from these stations each year for A1 and A2, respectively. (c) Average annual maximum 3-day precipitation total trends [calculated as in (a)] for periods with different start and end times using only stations with significant trends in each period. The top triangle in (c) is associated with significant trends in A1 and the bottom triangle is associated with significant trends in A2. The number of stations with significant trends at each period is shown in each box.

events in this region is 2.75 times as large as that in western United States (from 1950 to 2019, 5950 and 2160 R-CAT events were recorded in eastern and western United States, respectively). Thus, the overall change in average number of stations reaching R-CAT levels in the United States as a whole (gray bars) follows the same increasing pattern as in eastern U.S region (Fig. 10).

In Fig. 11, the frequency and areal extents of R-CAT episodes in the past decade are compared with those in 1950-2008 in eastern and western United States. Because the density of weather stations is different from the western region to eastern region (Fig. 1a), comparisons of numbers of stations per episode from west to east is less telling here than are comparisons from time period to time period, and within region among R-CAT levels. An increase in the frequency of all R-CAT episodes in eastern United States and R-CAT 1 episodes in western United States is observed in the past decade compared to 1950-2019 (Figs. 11b,c). The average areal extents of R-CAT episodes for all R-CAT levels across CONUS were larger during the past decade than in the longer historical record, except for R-CAT 1 episodes in western United States. In the western United States, the average areal extent of R-CAT 1 episodes declined slightly during the past decade (Fig. 11e). The significance of changes reported in this section cannot yet be 


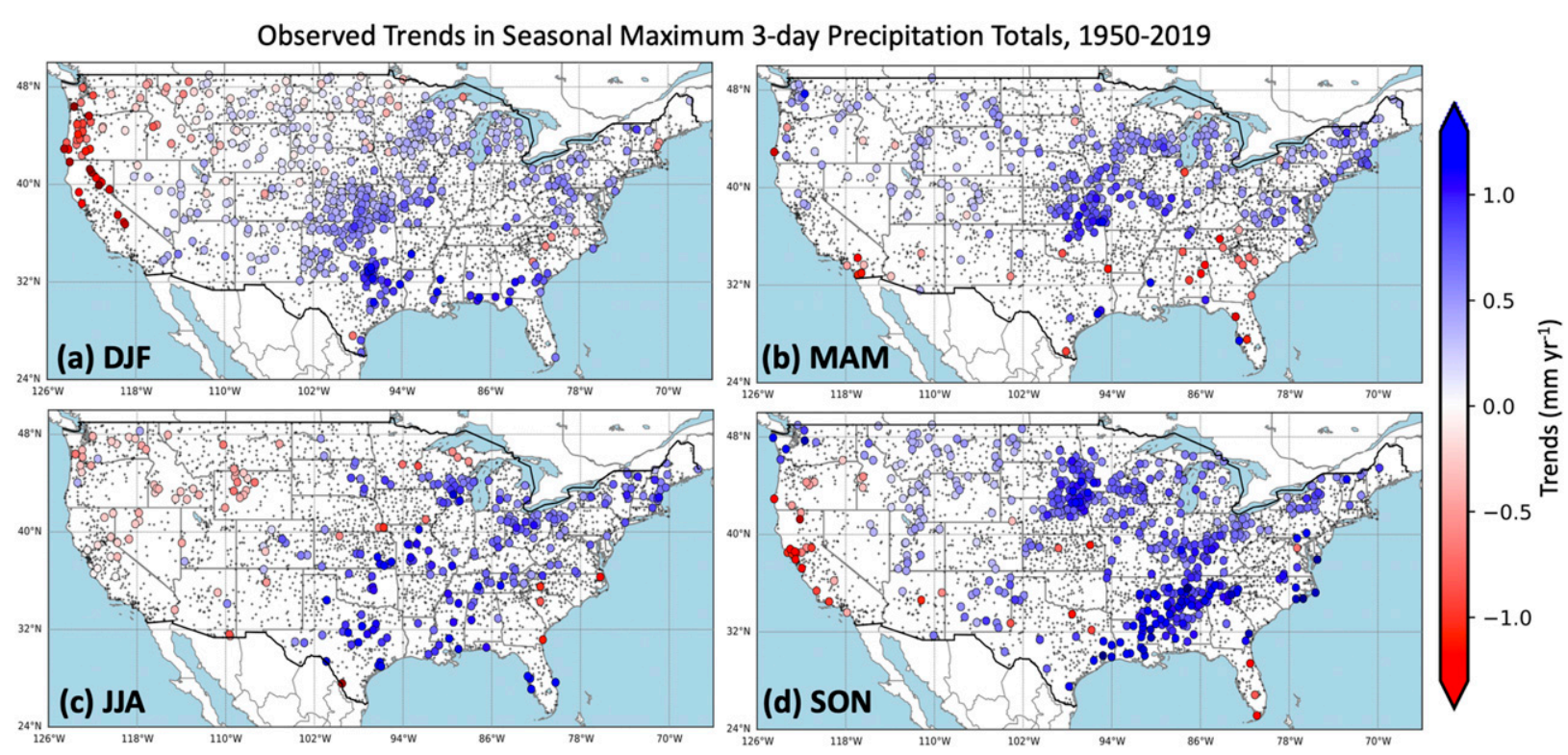

FIG. 9. As in Fig. 8a, but for seasonal maximum 3-day precipitation totals during (a) DJF, (b) MAM, (c) JJA, and (d) SON.

confirmed due to the small sample size afforded by these extreme R-CAT episodes.

How total precipitation is distributed among the several days of R-CAT events is an important characteristic that can affect resulting hydrologic impacts. Here, we evaluate changes in this characteristic of the strongest R-CAT episodes each year from 1950 to 2019 by calculating the ratio of average daily precipitation total to maximum daily precipitation total during R-CAT episodes presented in Fig. 7a (Fig. 7b). This ratio is an indication of how evenly precipitation is distributed during 3-day R-CAT time windows (for the largest
R-CAT event in strongest R-CAT episodes each year). Lower ratios indicate distributions with most of the precipitation falling in a single day, while higher ratios indicate precipitation that is more evenly distributed during the 3-day time window. An upward trend, even though not significant at $90 \%$ confidence level, is evident in Fig. 7b, so that from 1950 to 2019, the ratio of average to maximum daily precipitation total of the largest R-CAT event each year increases about $7 \%$, on average. This trend indicates that in contrast to past extreme R-CAT events, many recent events have been characterized by sustained extreme precipitation rather than by
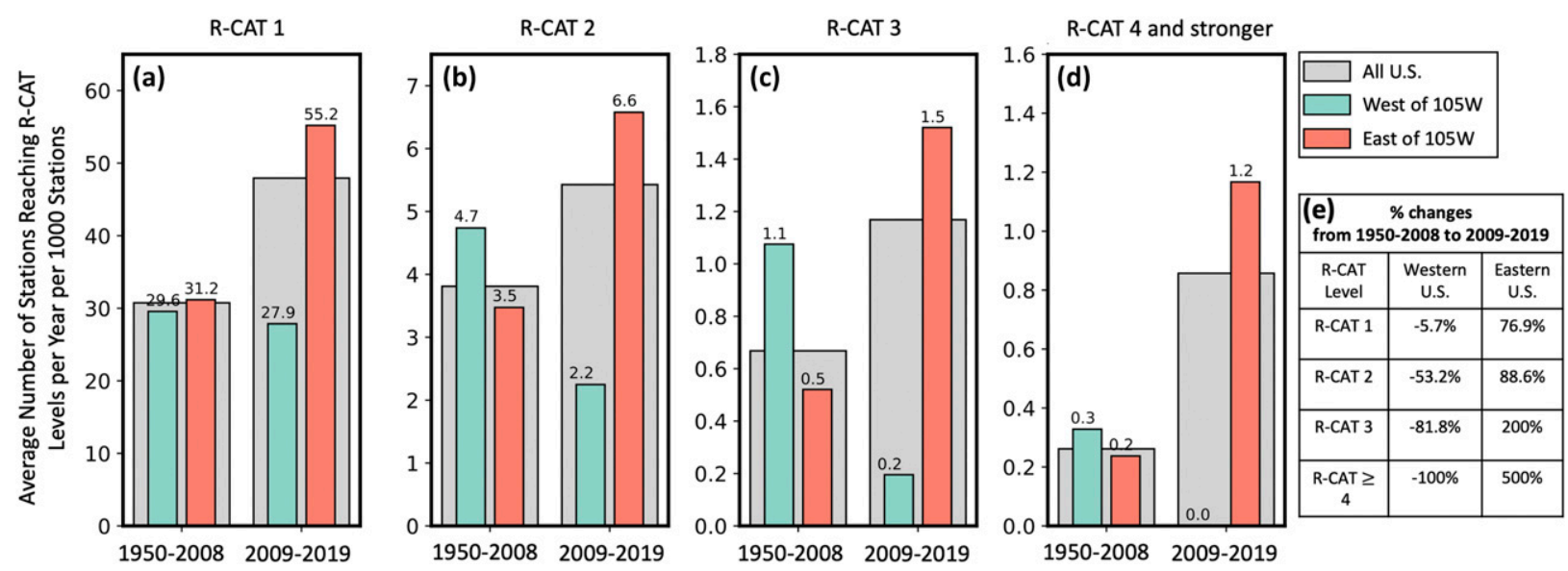

FIG. 10. Changes in average number of nonoverlapping R-CAT events per year per 1000 stations between 1950-2008 and 2009-19 for (a) R-CAT 1, (b) R-CAT 2, (c) R-CAT 3, and (d) R-CAT 4 and stronger events. (e) Percent changes from 1950-2008 to 2009-19 for western and eastern United States are summarized. 


\section{CONUS}
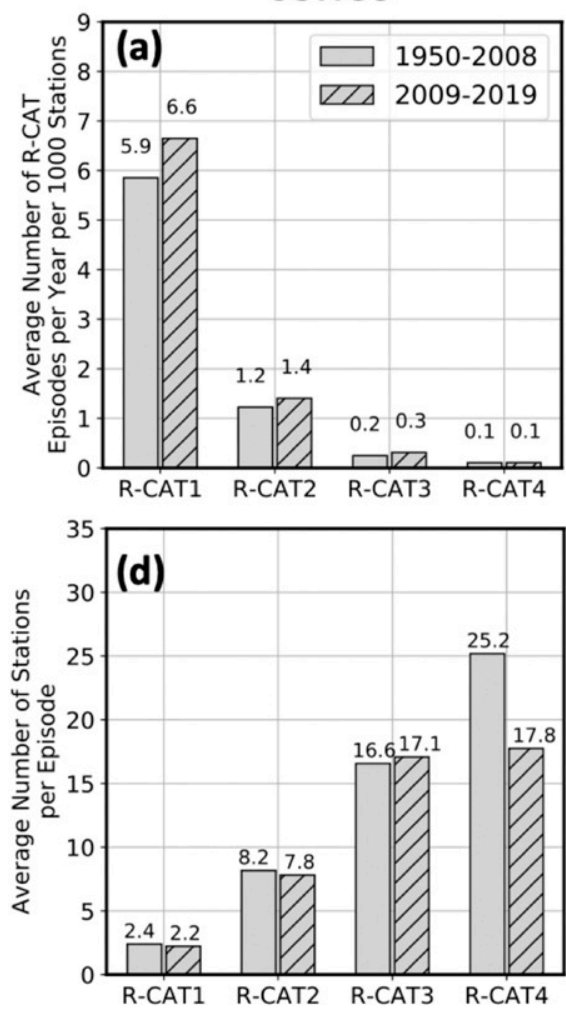

West of 105W
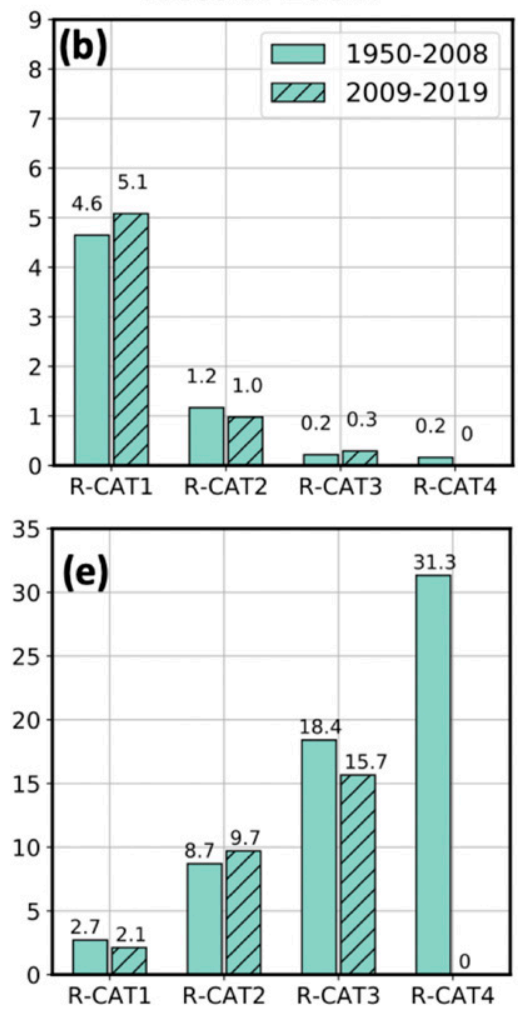

East of 105W
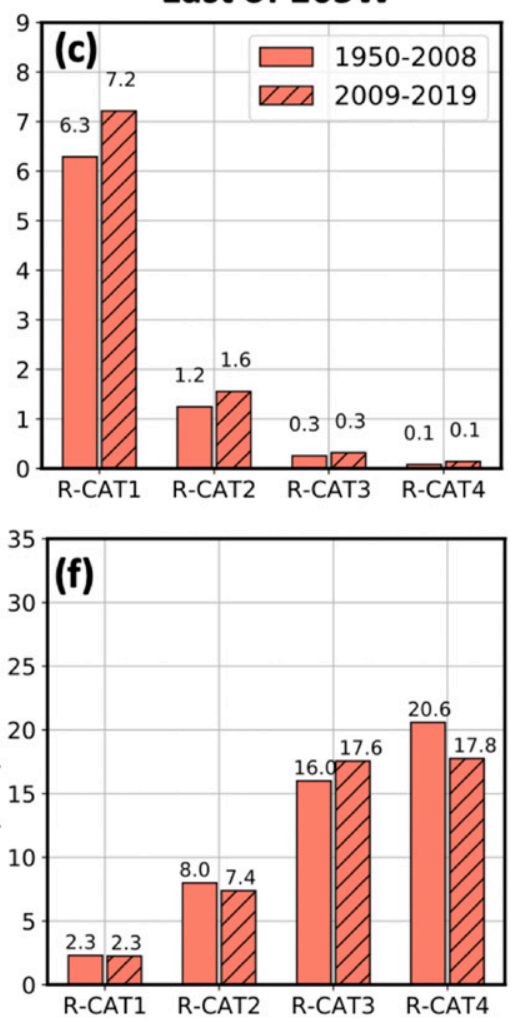

FIG. 11. Changes in characteristics of R-CAT episodes from 1950-2008 (solid color bars) to 2009-19 (hatched bars) for the conus (gray bars), western United States (green bars), and eastern United States (orange bars). Characteristics analyzed here include (a)-(c) average number of R-CAT episodes per year and (d)-(f) average number of stations reaching $200 \mathrm{~mm}$ precipitation totals in a 3 -day period during the episode.

single-day extremes, something that has not been reported previously in the historical record nor discussed much in climate change projections. This increase in the duration of extreme precipitation rates presumably underlies the kind of trends toward promotion of precipitation totals toward higher R-CAT levels, discussed earlier, in the eastern United States.

Characteristics of extreme, R-CAT level, storms between 1950-2008 and 2009-19 have been compared here. However, the back-to-back occurrence of the three of the four most extreme historical storms in 201719 that inspired this study limits how certainly we can interpret them in the long contexts of historical variability and evolving climate change. Exceptional events that fall in the final two or three years of the time series analyzed here, or in any set of multidecade time series, provide too limited a sample, and are too close to analytical edge effects, to determine whether they mark a new distribution or regime. Results here are intended to contextualize those recent most extreme storms. But only (further) time will show-with any great confidence-whether storms like Harvey, Florence, and
Imelda are examples of a changed probability distribution as opposed to reflecting only some really bad luck.

\section{Conclusions}

The R-CAT scale, which categorizes extreme precipitation based on very simple thresholds of 3-day precipitation totals, is applied in this study to daily precipitation observations from more than 3501 weather stations across the CONUS from 1950 to 2019. One goal is to describe climatological properties, including the frequencies and areal extents of the most extreme storms ever recorded at stations across the United States. Another goal is to contextualize several recent storms in the 2009-19 period that have deposited whole new extremes of precipitation. Furthermore, this paper evaluates the relative contributions of atmospheric rivers versus tropical storms to the historically most extreme precipitation totals on the West Coast and along the eastern seaboard of the United States.

In the 1950-2019 period, almost all R-CAT 2 and stronger events have been recorded along the Gulf Coast, southeast coast, and West Coast. The return 
periods of R-CAT events are shorter along the West Coast compared to the Gulf and East Coast regions; that is, many more R-CAT events have occurred at individual stations on the West Coast than on the east. The most extreme R-CAT events in CONUS have been recorded recently in eastern United States, during Hurricane Harvey (2017) and Hurricane Florence (2018), reaching R-CAT 9 and R-CAT 7, respectively. Meanwhile the most extreme R-CAT events ever recorded along the U.S. West Coast (since 1950) have only reached level 5.

October-March and March-October are the most active seasons for R-CAT storms in western and eastern United States, respectively, with the most extreme R-CAT storms being recorded in October and December in the West Coast and in August and September in the east. More than 90\% of R-CAT storms in western United States are caused by ARs, while $40 \%$ of R-CAT storms in eastern and Gulf coastal regions are associated with hurricanes and tropical storms, which are mixed with ARs $48 \%$ of the time.

Trend analyses of annual maximum 3-day precipitation totals show significant declines at many stations in Northern California and coastal Oregon. In eastern U.S. stations, significant increasing trends are observed in 339 stations, while only 11 stations indicate significant decreasing trends. Consistent with these results, the number of stations reaching R-CAT levels per year has been less, on average, in the western United States and more in the eastern United States in the past decade than over the 1950-2009 period. An analysis of changes in distribution of precipitation during the 3-day time window of the strongest R-CAT episodes each year in eastern United States indicates a possible shift toward a more evenly distributed precipitation during these storms, implying longer durations of the most extreme deluges. In fact, what made Harvey and Florence the most extreme R-CAT episodes recorded since 1950 was their large multiday average, rather than maximum, daily precipitation totals.

Hurricanes Harvey and Florence were of R-CAT levels 9 and 7, respectively, so extreme that their like has never been recorded anywhere across the CONUS in the 70-yr period of record analyzed here. The fact that these two storms have occurred among the three most recent years (with 2019's Tropical Storm Imelda not far behind) raises the question of whether they have been reflections of the changing climate or just been bad luck. Many studies have by now shown that we should expect more extreme storms using various combinations of models and observations, and these specific storms appear in recent attribution studies to owe much to the progress of climate change (e.g., for Hurricane Harvey; Risser and Wehner 2017; van Oldenborgh et al. 2017; Emanuel 2017; Wang et al. 2018). The present study based solely on observations was unable to show a clear shift in the distribution of R-CAT level storms in the past decade, primarily because a decade is too small a sample to demonstrate irreversible changes. Nonetheless, the severity of these recent storms provides, at least, a very good analog for what enhanced future storms may look like and what impacts they will bring, and also a red flag that those changes may already be upon us.

Acknowledgments. We thank three anonymous reviewers for their insightful and helpful comments. We thank Dr. Bin Guan for making the AR chronology available for this analysis. This chronology was retrieved from https:/ucla.app.box.com/v/ARcatalog/folder/ 16461222214. GHCN-Daily precipitation observations used here are downloaded from ftp://ftp.ncdc.noaa.gov/ pub/data/ghen/daily/by_year/.

\section{REFERENCES}

Alexander, L. V., and Coauthors, 2006: Global observed changes in daily climate extremes of temperature and precipitation. J. Geophys. Res., 111, D05109, https://doi.org/10.1029/ 2005JD006290.

American Meteorological Society, 2020: Atmospheric river. Glossary of Meteorology, http://glossary.ametsoc.org/wiki/Atmospheric_river.

Barlow, M., and Coauthors, 2019: North American extreme precipitation events and related large-scale meteorological patterns: A review of statistical methods, dynamics, modeling, and trends. Climate Dyn., 53, 6835-6875, https://doi.org/ 10.1007/s00382-019-04958-z.

Bishop, D. A., and Coauthors, 2019: Investigating the causes of increased twentieth-century fall precipitation over the southeastern United States. J. Climate, 32, 575-590, https://doi.org/ 10.1175/JCLI-D-18-0244.1.

Debbage, N., P. Miller, S. Poore, K. Morano, T. Mote, and J. M. Shepard, 2017: A climatology of atmospheric river interactions with the southeastern United States coastline. Int. J. Climatol., 37, 4077-4091, https://doi.org/10.1002/joc.5000.

Easterling, D. R., J. L. Evans, P. Y. Groisman, T. R. Karl, K. E. Kunkel, and P. Ambenje, 2000a: Observed variability and trends in extreme climate events: A brief review. Bull. Amer. Meteor. Soc., 81, 417-425, https://doi.org/10.1175/15200477(2000)081<0417:OVATIE > 2.3.CO;2.

- G. A. Meehl, C. Parmesan, S. A. Changnon, T. R. Karl, and L. O. Mearns, 2000b: Climate extremes: Observations, modeling, and impacts. Science, 289, 2068-2074, https://doi.org/ 10.1126/science.289.5487.2068.

Emanuel, K., 2017: Assessing the present and future probability of Hurricane Harvey's rainfall. Proc. Natl. Acad. Sci. USA, 114, 12 681-12 684, https://doi.org/10.1073/pnas.1716222114.

Groisman, P. Ya., and Coauthors, 1999: Changes in the probability of heavy precipitation: Important indicators of climatic change. Climatic Change, 42, 243-283, https://doi.org/10.1023/ A:1005432803188.

_, R. W. Knight, and T. R. Karl, 2001: Heavy precipitation and high streamflow in the contiguous United States: Trends in the twentieth century. Bull. Amer. Meteor. Soc., 82, 219-246, https:// doi.org/10.1175/1520-0477(2001)082<0219:HPAHSI >2.3.CO;2.

Guan, B., and D. E. Waliser, 2015: Detection of atmospheric rivers: Evaluation and application of an algorithm for global studies. 
J. Geophys. Res. Atmos., 120, 12 514-12 535, https://doi.org/ 10.1002/2015JD024257.

Higgins, R. W., and V. E. Kousky, 2013: Changes in observed daily precipitation over the United States between 1950-79 and 1980-2009. J. Hydrometeor., 14, 105-121, https://doi.org/10.1175/ JHM-D-12-062.1.

IPCC, 2012: Managing the Risks of Extreme Events and Disasters to Advance Climate Change Adaptation. Cambridge University Press, $582 \mathrm{pp}$.

Iwashima, T., and R. Yamamoto, 1993: A statistical analysis of the extreme events : Long-term trend of heavy daily precipitation. J. Meteor. Soc. Japan, 71, 637-640, https://doi.org/10.2151/ jmsj1965.71.5_637.

Jenner, L., 2019: September 2019-NASA estimates Imelda's extreme rainfall. NASA blog post, accessed 3 February 2020, https://blogs.nasa.gov/hurricanes/tag/imelda-2019/.

Karl, T. R., and R. W. Knight, 1998: Secular trends of precipitation amount, frequency, and intensity in the United States. Bull. Amer. Meteor. Soc., 79, 231-242, https://doi.org/10.1175/15200477(1998)079<0231:STOPAF $>2.0 . \mathrm{CO} ; 2$.

,-- , D. R. Easterling, and R. G. Quayle, 1996: Indices of climate change for the United States. Bull. Amer. Meteor. Soc., 77, 279-292, https://doi.org/10.1175/1520-0477(1996)077<0279: IOCCFT $>2.0 . \mathrm{CO} ; 2$.

Kunkel, K. E., 2003: North American trends in extreme precipitation. Nat. Hazards, 29, 291-305, https://doi.org/10.1023/A:1023694115864.

_, K. Andsager, and D. R. Easterling, 1999: Long-term trends in extreme precipitation events over the conterminous United States and Canada. J. Climate, 12, 2515-2527, https://doi.org/ 10.1175/1520-0442(1999)012<2515:LTTIEP>2.0.CO;2.

—, D. R. Easterling, D. A. R. Kristovich, B. Gleason, L. Stoecker, and R. Smith, 2010: Recent increases in U.S. heavy precipitation associated with tropical cyclones. Geophys. Res. Lett., 37, L24706, https://doi.org/10.1029/2010GL045164.

Mahoney, K., and Coauthors, 2016: Understanding the role of atmospheric rivers in heavy precipitation in the southeast United States. Mon. Wea. Rev., 144, 1617-1632, https:// doi.org/10.1175/MWR-D-15-0279.1.

Mantua, N. J., S. R. Hare, Y. Zhang, J. M. Wallace, and R. C. Francis, 1997: A Pacific interdecadal climate oscillation with impacts on salmon production. Bull. Amer. Meteor. Soc., 78, 1069-1079, https://doi.org/10.1175/1520-0477(1997)078<1069: APICOW $>2.0 . C O ; 2$.

McCabe, G. J., and M. D. Dettinger, 2002: Primary modes and predictability of year-to-year snowpack variations in the western United States from teleconnections with Pacific Ocean climate. J. Hydrometeor., 3, 13-25, https://doi.org/ 10.1175/1525-7541(2002)003<0013:PMAPOY >2.0.CO;2.

Menne, M. J., I. Durre, R. S. Vose, B. E. Gleason, and T. G. Houston, 2012: An overview of the global historical climatology network-daily database. J. Atmos. Oceanic Technol., 29, 897-910, https://doi.org/10.1175/JTECH-D-11-00103.1.

Miller, D. K., C. F. Miniat, R. M. Wooten, and A. P. Barros, 2019: An expanded investigation of atmospheric rivers in the southern Appalachian Mountains and their connections to landslides. Atmosphere, 10, 71, https://doi.org/10.3390/atmos10020071.

Milly, P. C. D., J. Betancourt, M. Falkenmark, R. M. Hirsch, Z. W. Kundzewicz, D. P. Lettenmaier, and R. J. Stouffer, 2008: Stationarity is dead: Whither water management? Science, 319, 573-574, https://doi.org/10.1126/science.1151915.
Moore, B. J., P. J. Neiman, F. M. Ralph, and F. E. Barthold, 2012: Physical processes associated with heavy flooding rainfall in Nashville, Tennessee, and vicinity during 1-2 May 2010: The role of an atmospheric river and mesoscale convective systems. Mon. Wea. Rev., 140, 358-378, https://doi.org/10.1175/ MWR-D-11-00126.1.

National Hurricane Center, 2018: Costliest U.S. tropical cyclones tables update. Accessed 5 January 2019, https://www.nhc.noaa.gov/ news/UpdatedCostliest.pdf.

Pacheco, S. E., 2017: Hurricane Harvey and climate change: The need for policy to protect children. Pediatr. Res., 83, 9-10, https://doi.org/10.1038/pr.2017.280.

Ralph, F. M., and M. D. Dettinger, 2012: Historical and national perspectives on extreme West Coast precipitation associated with atmospheric rivers during December 2010. Bull. Amer. Meteor. Soc., 93, 783-790, https://doi.org/10.1175/BAMS-D-11-00188.1.

, J. J. Rutz, J. M. Cordeira, M. D. Dettinger, M. Anderson, D. Reynolds, L. J. Schick, and C. Smallcomb, 2019: A scale to characterize the strength and impacts of atmospheric rivers. Bull. Amer. Meteor. Soc., 100, 269-289, https://doi.org/10.1175/ BAMS-D-18-0023.1.

Risser, M. D., and M. F. Wehner, 2017: Attributable human-induced changes in the likelihood and magnitude of the observed extreme precipitation during Hurricane Harvey. Geophys. Res. Lett., 44, 12 457-12 464, https://doi.org/10.1002/2017GL075888.

Schroeder, E. E., B. C. Massey, and E. H. Chin, 1987: Floods in Central Texas, August 1-4, 1978. USGS Professional Paper 1332, 39 pp., https://doi.org/10.3133/pp1332.

Slinskey, E. A., P. C. Loikith, D. E. Waliser, and A. Goodman, 2019: An extreme precipitation categorization scheme and its observational uncertainty over the continental United States. J. Hydrometeor., 20, 1029-1052, https://doi.org/10.1175/ JHM-D-18-0148.1.

Stegner, W., 1953: Beyond the Hundredth Meridian-John Wesley Powell and the Second Opening of the West. Penguin Books, $496 \mathrm{pp}$.

USGCRP, 2017: Climate Science Special Report: Fourth National Climate Assessment, Volume I. D. J. Wuebbles et al., Eds., U.S. Global Change Research Program, 470 pp., https://doi.org/ 10.7930/J0J964J6.

Vahedifard, F., A. AghaKouchak, E. Ragno, S. Shahrokhabadi, and I. Mallakpour, 2017: Lessons from the Oroville dam. Science, 355, 1139-1140, https://doi.org/10.1126/science.aan0171.

van Oldenborgh, G. J., and Coauthors, 2017: Attribution of extreme rainfall from hurricane Harvey, August 2017. Environ. Res. Lett., 12, 124009, https://doi.org/10.1088/1748-9326/aa9ef2.

Vano, J. A., K. Miller, M. D. Dettinger, R. Cifelli, D. Curtis, A. Dufour, J. R. Olsen, and A. M. Wilson, 2019: Hydroclimatic extremes as challenges for the water management community: Lessons from Oroville dam and Hurricane Harvey. Bull. Amer. Meteor. Soc., 100, S9-S14, https://doi.org/10.1175/BAMS-D-18-0219.1.

Wang, S.-Y. S., L. Zhao, J.-H. Yoon, P. Klotzbach, and R. R. Gillies, 2018: Quantitative attribution of climate effects on Hurricane Harvey's extreme rainfall in Texas. Environ. Res. Lett., 13, 054014, https://doi.org/10.1088/1748-9326/aabb85.

White, A. B., B. J. Moore, D. J. Gottas, and P. J. Neiman, 2019: Winter storm conditions leading to excessive runoff above California's Oroville Dam during January and February 2019. Bull. Amer. Meteor. Soc., 100, 55-70, https://doi.org/10.1175/BAMS-D-18-0091.1. 